\title{
Impact of horizontal resolution on prediction of tropical cyclones over Bay of Bengal using a regional weather prediction model
}

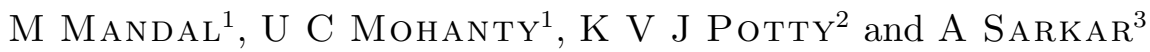 \\ ${ }^{1}$ Centre for Atmospheric Sciences, Indian Institute of Technology, Hauz Khas, New Delhi 110 016, India. \\ ${ }^{2}$ Alfred Wegener Institute for Polar and Marine Research, Bremerhaven, Germany. \\ ${ }^{3}$ Modi College of Engineering and Technology, Lakshmangarh, Sikar, India.
}

The present study is carried out to examine the performance of a regional atmospheric model in forecasting tropical cyclones over the Bay of Bengal and its sensitivity to horizontal resolution. Two cyclones, which formed over the Bay of Bengal during the years 1995 and 1997, are simulated using a regional weather prediction model with two horizontal resolutions of $165 \mathrm{~km}$ and $55 \mathrm{~km}$. The model is found to perform reasonably well towards simulation of the storms. The structure, intensity and track of the cyclones are found to be better simulated by finer resolution of the model as compared to the coarse resolution. Rainfall amount and its distribution are also found to be sensitive to the model horizontal resolution. Other important fields, viz., vertical velocity, horizontal divergence and horizontal moisture flux are also found to be sensitive to model horizontal resolution and are better simulated by the model with finer horizontal grids.

\section{Introduction}

Tropical cyclones are one of the most devastating and deadliest meteorological phenomena. Strong winds, torrential rainfall and worst of all, the associated storm surges are the three major elements of the tropical cyclone disaster. The Indian subcontinent is one of the worst affected parts of the world as far as associated death toll are concerned. The causality figures associated with major cyclones in the Indian sub-continent in the recent past are 2,00,000 and 1,31,000 in Bangladesh in 1971 and 1991; 10,000 and 1000 in 1977 and 1990 in Andhra Pradesh (India). The super cyclone that crossed Orissa (India) coast on 29th November, 1999 affected 129.66 lakh people $(10,000$ people killed) and caused huge damage to properties. Timely and reasonably accurate forecast of these cyclones can save lots of lives and huge damage to properties. Therefore, the accurate pre- diction of tropical cyclones in this region is of great importance.

During the last two decades, there have been considerable improvements in the prediction of tropical cyclones by numerical models. High resolution regional models as well as global models are now being extensively used by most of the leading weather prediction centers around the world. Some of the models that are in use for the prediction of tropical cyclones are Typhoon Model (TYM) for western North Pacific (Iwasaki et al 1987), Quasi-Lagrangian Model (QLM) for U.S (Mathur 1991), Geophysical Fluid Dynamics Laboratory (GFDL) model (Kurihara et al 1993, 1995) and BMRC model for Australia (Puri et al 1992). In the last half decade, the focus is on the use of high-resolution hydrostatic/nonhydrostatic regional/mesoscale models for prediction of tropical storms. PSU/NCAR mesoscale model known as MM5 has been used

Keywords. Tropical cyclone; resolution; track; regional model. 
in a number of studies for the simulation of tropical cyclones (Karyampudi et al 1998) including some at very high resolution (Liu et al 1997, 1999 and Braun and Tao 2000). In India, Prasad (1990), Prasad et al (1992, 1997) proposed a scheme for generating synthetic vortex in initializing a limited area primitive equation model for tropical cyclone forecast over the Bay of Bengal. Gupta et al (1997) showed the impact of insertion of bogus vortex in the model analysis on the prediction of tropical cyclones over Indian seas using a global spectral model. Patra et al (2000) made a comparative study on the performance of MM5 and RAMS models in simulating the Bay of Bengal cyclones. Bhaskar Rao et al (1999) used an axi-symmetric primitive equation model with Arakawa-Schubert cumulus parameterization scheme to simulate tropical cyclones over the Bay of Bengal. Mohanty and Mandal (2003) used MM5 model for simulation of Orissa super cyclone that hit Orissa coast on the 29th October 1999.

The model horizontal resolution is an important issue in present day numerical weather prediction, particularly in tropical cyclone prediction. Delineation of fine structure of the large-scale phenomenon by numerical model is very important for accurate prediction of intensity and movement of the cyclone. A regional model can capture the fine structure of the cyclones, if the model resolution is increased sufficiently. The topographic features and sub-grid scale physical processes are better represented with increase in horizontal resolution of the model. Further, all physical parameterizations in a numerical model are sensitive to model horizontal resolution. In his study on monsoon prediction at different resolutions with a global spectral model Krishnamurti (1990) found that the higher resolution models simulate more realistic precipitation. Giorgi and Marinucci (1996) in their sensitivity experiment found that the model simulated precipitation amount is sensitive to grid spacing. Zhongbo $\mathrm{Yu}$ et al (1999) studied the impact of model horizontal resolution in simulation of precipitation associated with two storms over Susquehanna River Basin. Version 1 of MM5 model with horizontal resolution of $36 \mathrm{~km}, 12 \mathrm{~km}, 4 \mathrm{~km}$ was used in the study. The range of cumulative precipitation and precipitation rate at each time step is found to increase as the model grid spacing decreases.

After the introduction, the model description follows in section 2. Various numerical experiments and used data sets are described in section 3 . Results of the model simulation and analysis maps are presented in section 4. Finally conclusions are presented in section 5 .

\section{Model description}

The model used in this study is a modified version of the regional model developed in collaboration with the Naval Research Laboratory (NRL) and North Carolina State University (Madala et al 1987). This is a limited area, multi-level primitive equation model incorporating boundary layer and cumulus parameterization schemes as well as varying topography. The governing equations are in surface pressure weighted flux form and represented in the normalized pressure based terrain following $\sigma\left(p / p_{s}\right)$ vertical co-ordinate system. The system of seven equations (five prognostic and two diagnostic) includes the zonal and meridional components of momentum equation, thermodynamic equation, the moisture continuity equation, the surface pressure tendency equation, the hydrostatic equation and the mass continuity equation. These equations form a closed system for the seven basic variables namely zonal wind $(u)$, meridional wind $(v)$, temperature $(T)$, specific humidity $(q)$, surface pressure $\left(p_{s}\right)$, geopotential $(\phi)$ and vertical velocity $(\dot{\sigma})$. The horizontal grid is staggered one (Arakawa C-grid) with temperature, specific humidity, geopotential, surface pressure and $\dot{\sigma}$ is specified at the mass points, zonal wind is specified at the middle of two successive mass points along the zonal direction and meridional wind is specified at the middle of two successive mass points in the meridional direction. $\dot{\sigma}$ is computed at $\frac{1}{2} \sigma$ levels. The finite difference scheme used is of second order accuracy. The split explicit time integration scheme (Madala 1978) is used in the model, which allows us to use different time steps for the slow moving Rossby modes and fast moving gravity modes. Shorter time step is used for the fast moving gravity modes and longer time step is used for the slower moving Rossby modes. The domain and horizontal resolution of the model are user specified. The integration time step is also user specified. At the lateral boundaries, Perkey and Kreitzberg (1976) sponge boundary condition is employed. Dry convective adjustment, large-scale precipitation, convective precipitation and planetary boundary layer are the physical processes included in the model. The boundary layer parameterization includes surface layer and mixed layer parameterization. The surface layer parameterization is based on Monin-Obukhov similarity theory and the mixed layer incorporates Turbulent Kinetic Energy (TKE) 1.5 closure scheme. The cumulus convection parameterization is based on modified Kuo scheme (Kuo 1974; Anthes 1977). An overview of the model is given in table 1. A detailed discussion on the model is given by Madala et al (1987). 
Table 1. An overview of the model.

\begin{tabular}{ll}
\hline \multicolumn{1}{c}{ Domain } & $54^{\circ} \mathrm{E}-114^{\circ} \mathrm{E}, 3^{\circ} \mathrm{S}-45^{\circ} \mathrm{N}$ \\
\hline Independent variables & $\lambda, \phi, \sigma, \mathrm{t}$ \\
\hline Prognostic variables & $\mathrm{u}, \mathrm{v}, \mathrm{T}, \mathrm{q}, \mathrm{p}_{\mathrm{s}}$ \\
\hline Diagnostic variables & $\phi, \dot{\sigma}$ \\
\hline Topography & Envelope (Mean +1 std.) \\
\hline Vertical levels & 16 vertical levels in sigma co-ordinate \\
\hline Full sigma levels & $0.05,0.15,0.25,0.35,0.45,0.55,0.65,0.75,0.82,0.86$, \\
& $0.90,0.935,0.96,0.975,0.987,0.997$ \\
\hline Horizontal grid system & Arakawa C-grid \\
\hline Time integration scheme & Leapfrog split-explicit time integration scheme \\
\hline Horizontal grid spacing & $1.5^{\circ}$ latitude/longitude in CD \\
\hline Time step & $0.5^{\circ}$ latitude/longitude in FD \\
\hline Horizontal diffusion & 270 sec for CD \\
\hline Initialization & 90 sec for FD \\
\hline Physical parameterization & Linear second order \\
& Non linear normal mode \\
\hline & Dry convective adjustment, Modified Kuo cumulus con- \\
& vective parameterization scheme (Anthes 1977), Large \\
\hline & scale precipitation with $\mathrm{R}_{h}>95 \%$, TKE PBL parame- \\
& terization scheme. \\
\hline
\end{tabular}

\section{Experiment design and data}

The regional model described in section 2 is used to simulate two Bay of Bengal cyclones with model horizontal resolutions $165 \mathrm{~km}$ and $55 \mathrm{~km}$. The model with resolution $165 \mathrm{~km}$ is referred to as coarse domain (CD) and that of $55 \mathrm{~km}$ as fine domain (FD). For both resolutions the model domain is kept the same, $54^{\circ}$ East to $114^{\circ}$ East in the east-west direction and $3^{\circ}$ South to $45^{\circ}$ North in the north-south direction. From US Navy $10^{\prime} \times$ $10^{\prime}$ orography data, envelope topography (mean +1 standard deviation) is prepared for the corresponding resolution and used in the model.

In November 1995, a deep depression formed over the Bay of Bengal was intensified into a cyclonic storm by 0000 UTC of 8th November and centered near $13^{\circ} \mathrm{N}$ and $88.5^{\circ} \mathrm{E}$ (figure 1). Thereafter, it was intensified and moved almost in northerly direction with an average speed of $30 \mathrm{~km} / \mathrm{hr}$. Moving with the same speed and in the same direction it crossed north Andhra PradeshOrissa coast around 0500 UTC of 9th November, 1995. This is taken as case 1 . In case 2, the low pressure formed over the southeast Bay of Bengal in the morning of 15th May, 1997 intensified into a severe cyclonic storm by the morning of 17 th May and crossed Bangladesh coast at 1430 UTC of 19th May. For both the cases, the analysis from the global analysis and forecast system in operation at the National Center for Medium Range Weather Forecasting (NCMRWF), New Delhi is used as the initial condition. In case 1 , the NCMRWF analysis at 0000 UTC on 8th November 1995 is used as model initial condition and in case 2, analyzed data at 0000 UTC on 17th May 1997 is used as initial condition. National Center for Environmental Prediction (NCEP), USA reanalysis of sea surface temperature for the corresponding days are also used for model integration. In both the cases the model is integrated for 48 hours with time steps of $90 \mathrm{sec}$. and $270 \mathrm{sec}$. for the fine domain and coarse domain respectively. Figure 1(a) and (b) represents the mean sea level pressure at 0000 UTC on 8th November 1995 and 17th May 1997, which are the model initial conditions for case 1 and case 2 respectively. The above mentioned two cyclones occurred in two different cyclone seasons, premonsoon and post-monsoon and also hitting two different coasts, India and Bangladesh. That's why these two cases have been selected for the study.

\section{Results and discussion}

Figure 1(c) and (d) shows the envelope topography with $165 \mathrm{~km}$ and $55 \mathrm{~km}$ horizontal resolutions respectively. It is evident from the figure that the representation of topography can be improved by increasing the resolution. A marked increase of terrain gradient is noticed with increased resolution from 165 to $55 \mathrm{~km}$. Another noticeable improvement feature is that the orography is spreading more towards the oceanic region in the coarse grid 
(a) Initial condition case-1.

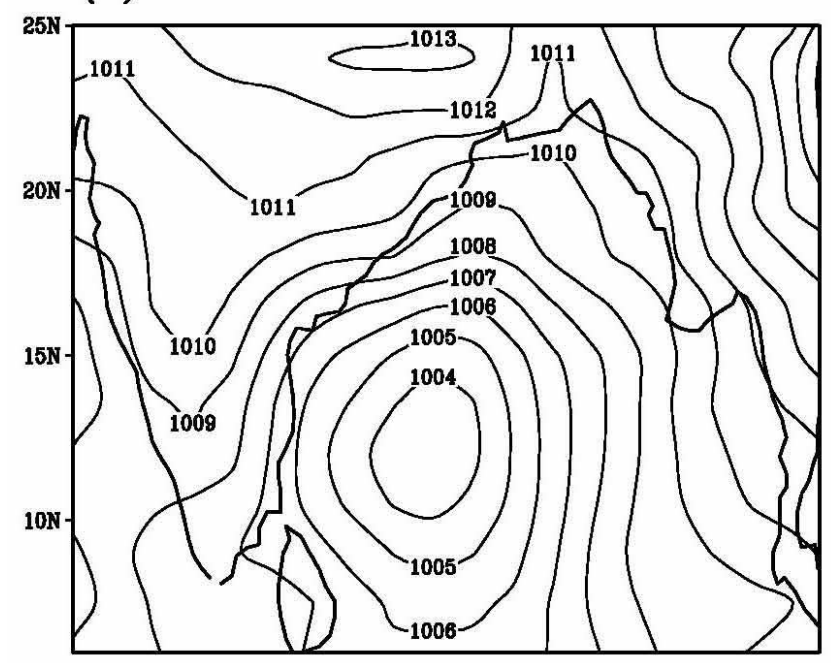

(b) Initial condition case-2.

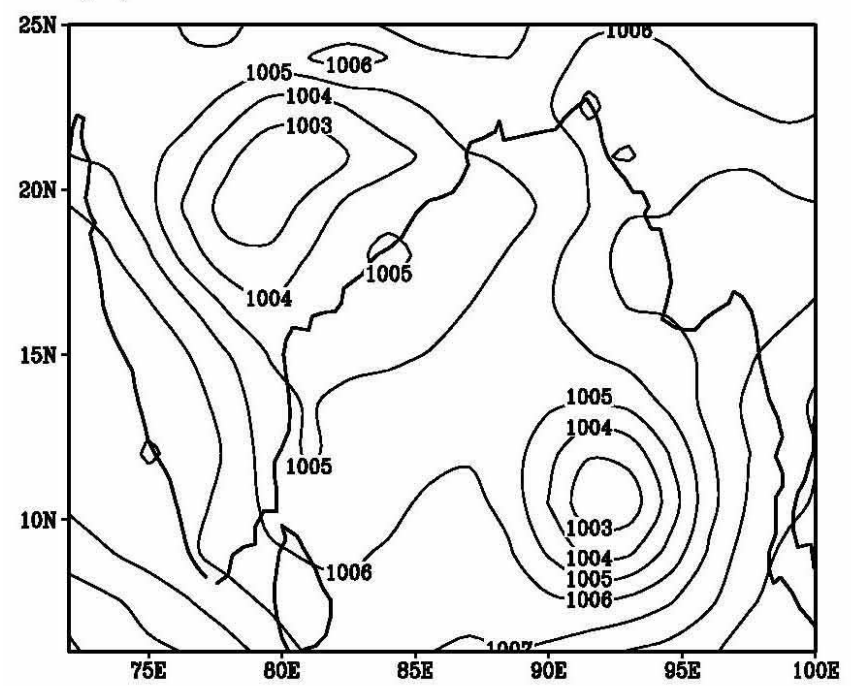

(c)

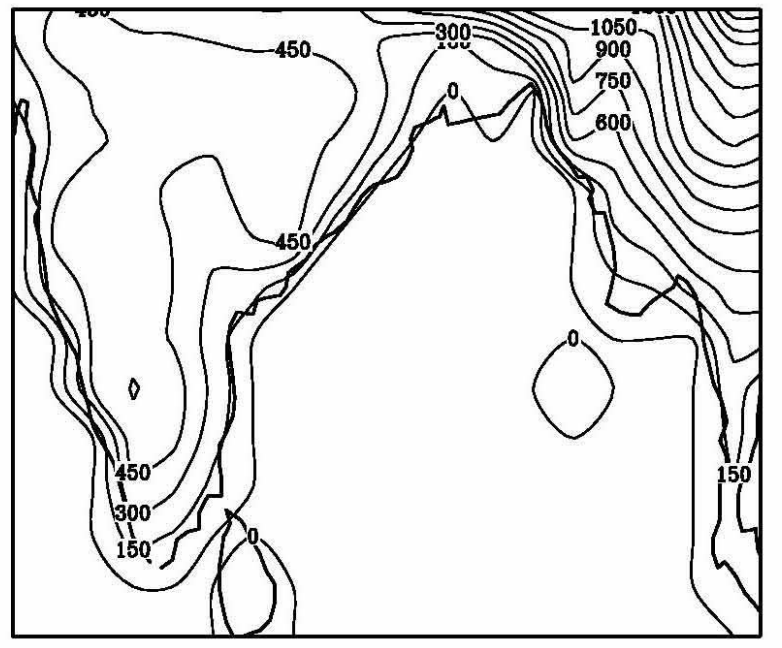

(d)

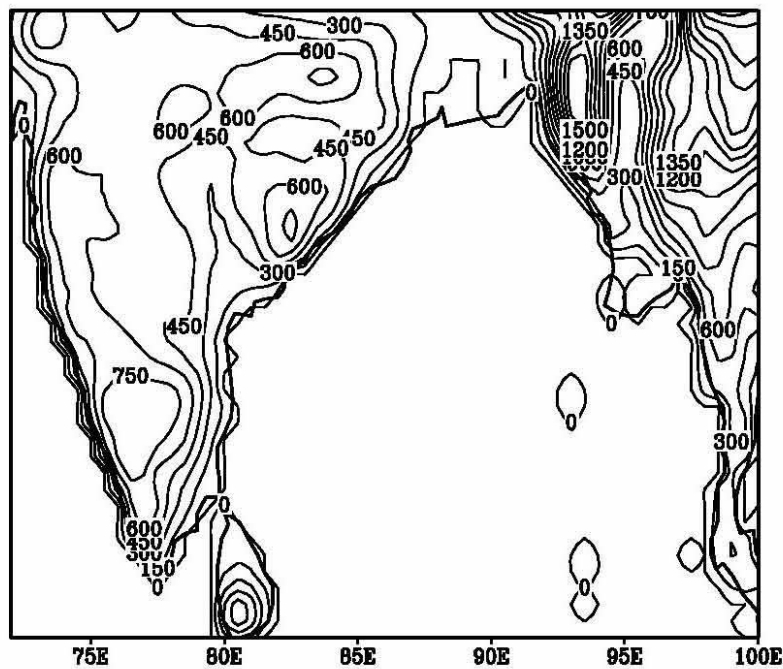

Figure 1. Mean sea level pressure at the start time of model integration for case 1 and case 2 and topography with two different model resolutions; (a) Mean sea level pressure on 8th Nov. '95 (00 UTC), (b) Mean sea level pressure on 17th May '97 (00 UTC), (c) $1.5 \mathrm{deg}$. resolution topography, (d) $0.5 \mathrm{deg}$. resolution topography.

representation (up to $1.32^{\circ}$ ) than that represented by the fine grid $\left(0.418^{\circ}\right)$.

\subsection{Mean sea level pressure}

Figure 2(a) represents the verification analysis of mean sea level pressure valid at 0000 UTC of 9th November 1995 for the first case. The figure shows that the system is intensified and moved to the north of northwesterly direction and centered near $84^{\circ} \mathrm{E}$ and $18^{\circ} \mathrm{N}$ with central mean sea level pressure of $999 \mathrm{hPa}$. Figure 2(b) and (c) illustrates day-1 (24 hours) forecast of mean sea level pressure valid at 0000 UTC of 9 th November 1995 by the CD and FD respectively. In the model forecast, both by CD and FD, the movement of the system is found to be slower but in the same direction as the analysis. The isobars are found to be elongated in the north-south direction unlike the analysis where it is almost symmetric around the cyclone center. The overall pressure distribution pattern given by FD is found to be very close to the analysis whereas an overall higher pressure is predicted by CD. The central pressures are found to be $999 \mathrm{hPa}, 1003 \mathrm{hPa}$ and $1008 \mathrm{hPa}$ in the analysis, FD and CD forecasts respectively. The position and intensity of the cyclone is found to be better simulated by FD than $\mathrm{CD}$. The position of eye as simulated by $\mathrm{CD}$ is at $82.5^{\circ} \mathrm{E}$ and $15^{\circ} \mathrm{N}$ whereas that simulated by the FD is at $83^{\circ} \mathrm{E}$ and $16^{\circ} \mathrm{N}$.

Figure 2(d) shows analysis of mean sea level pressure valid at 0000 UTC of 10th November 1995. 
(a) Analysis DAY-1 Case-1.

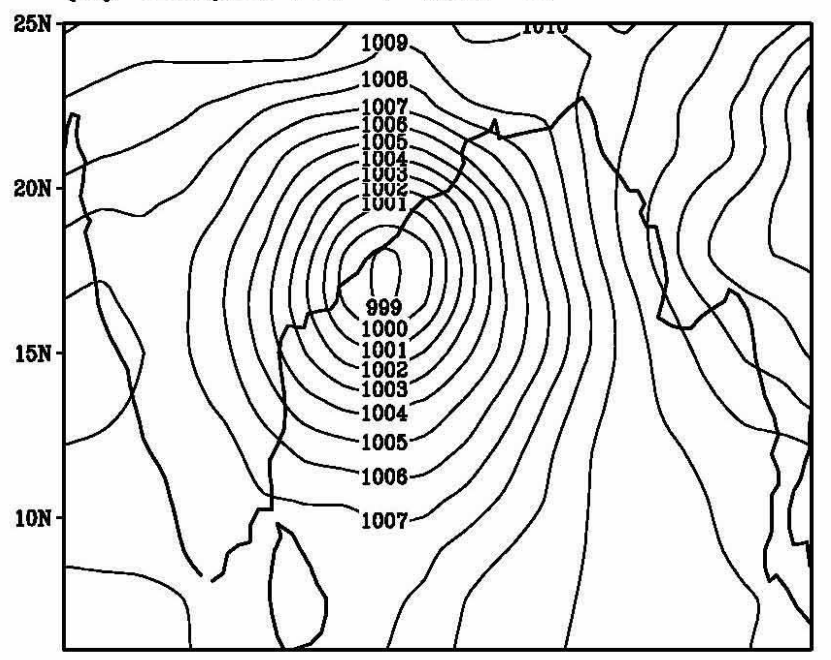

(b) FCST DAY-1 Case-1 by CD.

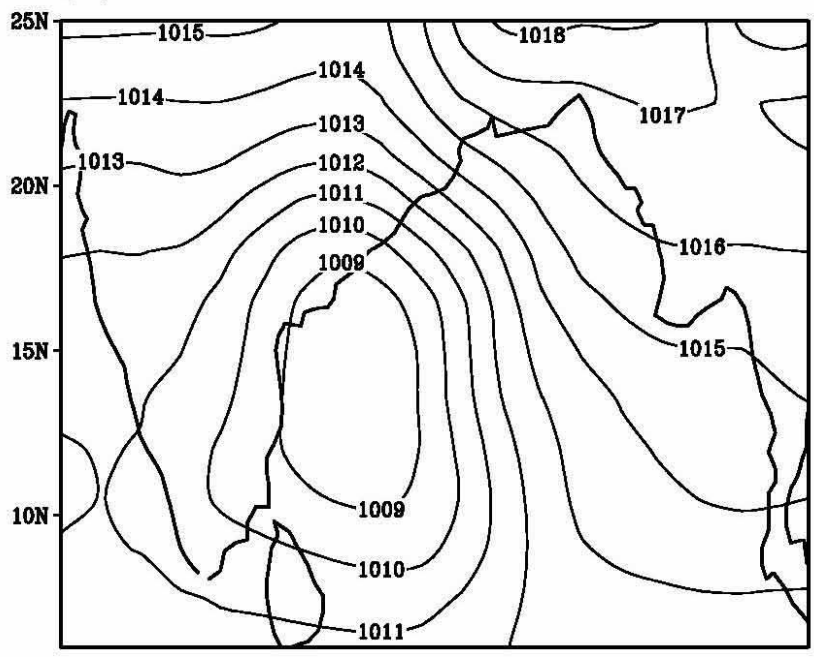

(c) FCST DAY-1 Case-1 by FD.

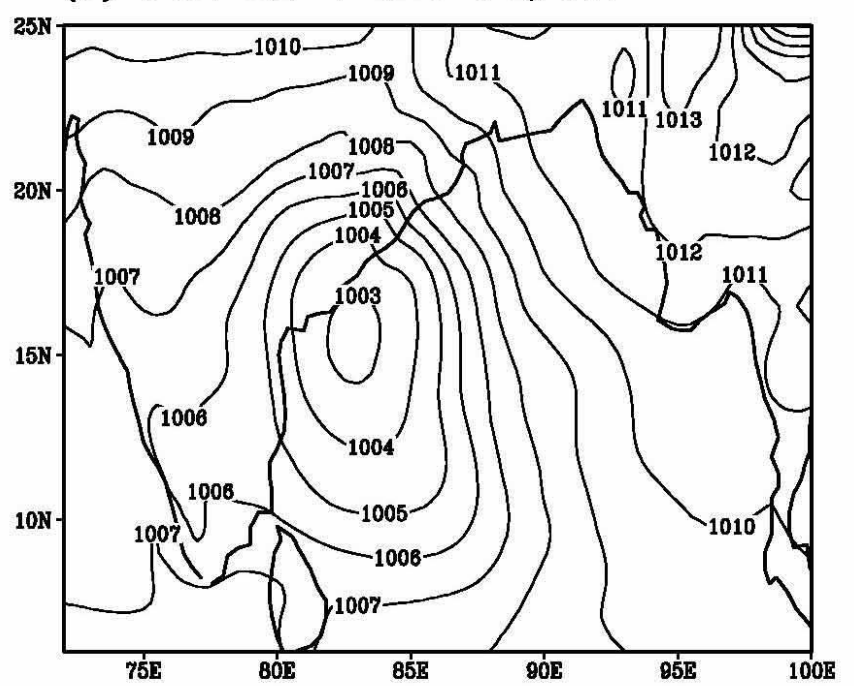

(d) Analysis DAY-2 Case-1.

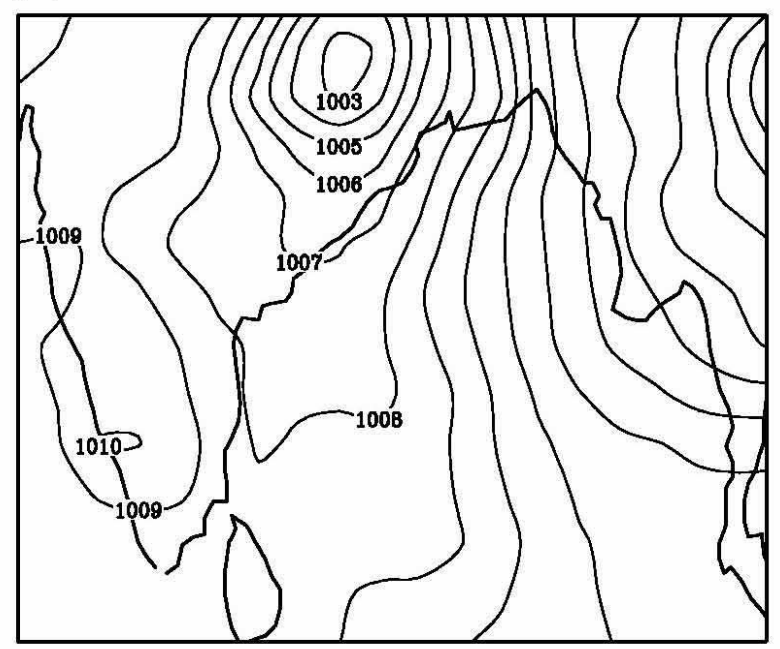

(e) FCST DAY-2 Case-1 by CD.

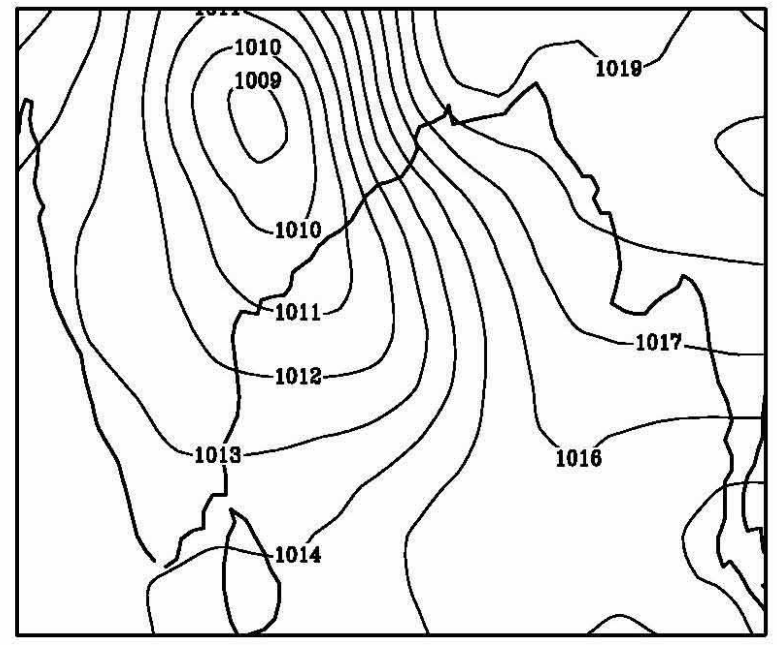

(f) FCST DAY-2 Case-1 by FD.

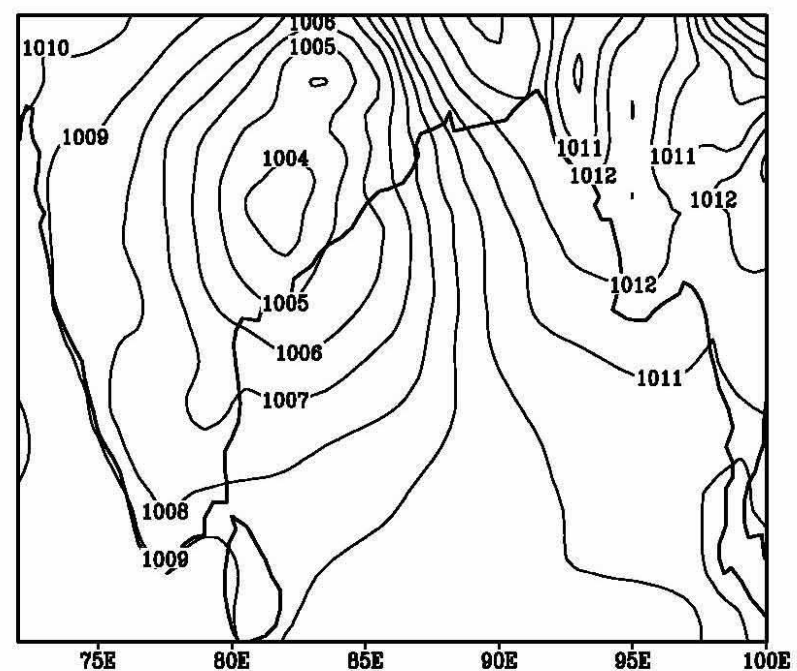

Figure 2. Verification analysis and forecast of mean sea level pressure (all at 00 UTC); (a) analysis on 9th Nov.'95, (b) 24-hours forecast valid on 9th Nov.'95 by coarse domain (CD), (c) 24-hours forecast valid on 9th Nov.' 95 by fine domain (FD), (d) analysis on 10th Nov.'95, (e) 48-hours forecast valid on 10th Nov.'95 by coarse domain (CD), (f) 48-hours forecast valid on 10th Nov.'95 by fine domain (FD). 
This indicates that the system is weakened in the last 24 hours as expected after landfall. Figure 2(e) and (f) illustrates day-2 mean sea level pressure forecast valid at 0000 UTC of 10th November 1995 by CD and FD respectively. Both the figures show breakup of the vortex into two cells. Similar to day1 forecast, day-2 forecast by FD is closer to analysis. The central pressures are found to be $1004 \mathrm{hPa}$ and $1008 \mathrm{hPa}$ in FD and CD forecasts respectively compared to $1003 \mathrm{hPa}$ in the analysis. FD forecast shows that the system is slightly weakened as expected after landfall whereas CD forecast maintains constant central pressure.

Figure 3 (a) to (c) presents the verification analysis and day- 1 forecast of mean sea level pressure by CD and FD respectively valid at 0000 UTC of 18 th May 1997 for the second case. Figure 3(a) shows that the storm is centered at $94.5^{\circ} \mathrm{E}$ and $16.5^{\circ} \mathrm{N}$. Apart from the cyclonic storm, one depression is also observed over Andhra Pradesh. This depression appeared in model simulation also. Position of the system is predicted reasonably well in both $\mathrm{CD}$ and FD forecasts. The magnitude of mean sea level pressure in CD forecast is found to be closer to the analysis whereas it is about $2 \mathrm{hPa}$ less in $\mathrm{FD}$ forecast. This is due to the fact that the mesoscale features are smoothed out in the coarse resolution verification analysis.

Figure $3(\mathrm{~d})$ to (f) shows verification analysis and day-2 forecast of mean sea level pressure by $\mathrm{CD}$ and FD respectively valid at 0000 UTC of 19 th May 1997. The FD forecast shows break up of the vortex into two cells. The location of the upper cell is close to the position of the storm in the analysis. The lower cell (stronger vortex) is close to the observed location of the storm at $90.8^{\circ} \mathrm{E}$ and $20^{\circ} \mathrm{N}$. In both day- 1 and day- 2 forecast, the minimum sea level pressure is found to be over the depression over Andhra Pradesh than over the cyclonic storm. It is probably due to the initial condition provided to the model (figure 1b). Initial condition shows the depression and cyclonic storm to be with the same central pressures in contrary to the observation showing the cyclonic storm with much lower pressure than the depression. In this case also FD forecast is found to be better than $\mathrm{CD}$ forecast both in respect to position and intensity. In FD forecast the intensity of the storm is improved by $2 \mathrm{hPa}$ both in day- 1 and day- 2 .

\subsection{Wind at $850 \mathrm{hPa}$}

Figure 4(a) and (d) represents the analyzed $850 \mathrm{hPa}$ wind vector at $0000 \mathrm{UTC}$ of 9 th and $10 \mathrm{th}$ November 1995 respectively. Both figures show stronger wind in the east and northeast sector of the cyclonic storm. Figure 4(b) and (c) illustrates day- 1 forecast of wind vector at $850 \mathrm{hPa}$ valid at
0000 UTC of 9th November 1995 by CD and FD respectively. The system is found to be elongated in the north-south direction in both forecasts unlike in the case of analysis, where it is almost symmetric around the storm center. Both forecasts are well in agreement with the analysis except this northsouth elongation. Figure 4(e) and (f) show the day2 forecast of wind vector at $850 \mathrm{hPa}$ for case 1 by $\mathrm{CD}$ and FD respectively. In analysis and FD forecast the maximum wind around the storm center is $21 \mathrm{~m} / \mathrm{sec}$. and in CD forecast it is $18 \mathrm{~m} / \mathrm{sec}$. In other parts of the domain both CD and FD forecasts are found to match reasonably well with the analysis. Wind speed around the storm center is slightly under-predicted in both CD and FD forecast and that may be the reason for slow movement of the system. The flow pattern and magnitude of wind is slightly better predicted in FD forecast on day-1 as well as on day-2. Analysis for day-1 and day-2 show that the maximum wind speed is in the eastern side of the storm. This feature is well predicted by both versions of the model. Similar results are obtained in case 2 as well (not shown).

Geopotential height and temperature are also found to be better simulated in FD forecast compared to CD (figures not shown). There are reductions in temperature forecast errors by $1^{\circ} \mathrm{C}$ and $2-3^{\circ} \mathrm{C}$ on day- 1 and day- 2 forecasts respectively with the use of finer horizontal resolution.

\subsection{Precipitation}

Figure 5(a) shows the analyzed 24 hours accumulated precipitation valid at 0300 UTC of 9th November 1995 as obtained from the NCMRWF. This shows rainfall over Andhra Pradesh, Orissa, West Bengal and over large areas of the Bay of Bengal. Maximum precipitation of $11.3 \mathrm{~cm}$ is located close to Bhubaneshwar in Orissa at about $86^{\circ} \mathrm{E}$ and $20.5^{\circ} \mathrm{N}$. India Meteorological Department (IMD) recorded maximum precipitation of $27 \mathrm{~cm}$ at Kalingpatnam in Andhra Pradesh. $13 \mathrm{~cm}$ precipitation is recorded over Bhubaneshwar and Gopalpur region in Orissa. Figure 5(b) and (c) represent 24 hours accumulated precipitation as obtained from $\mathrm{CD}$ and $\mathrm{FD}$ forecast respectively. Heavy precipitation is predicted in both the cases along the track of the cyclone. The distribution of rainfall, particularly in FD forecast matches reasonably well with the analysis. CD forecast shows maximum precipitation of $13 \mathrm{~cm}$ around $87^{\circ} \mathrm{E}$ and $18^{\circ} \mathrm{N}$ over the ocean. $4 \mathrm{~cm}$ of rainfall is simulated over Gopalpur and Bhubaneshwar and only $1.5 \mathrm{~cm}$ over Kalingapatnam. FD forecast gives $9 \mathrm{~cm}(13 \mathrm{~cm}$ in observation) precipitation over Gopalpur and Bhubaneshwar and $4 \mathrm{~cm}$ over Kalingapatnam. The maximum precipitation of $28 \mathrm{~cm}$ is predicted to the 
(a) Analysis DAY-1 Case-2.

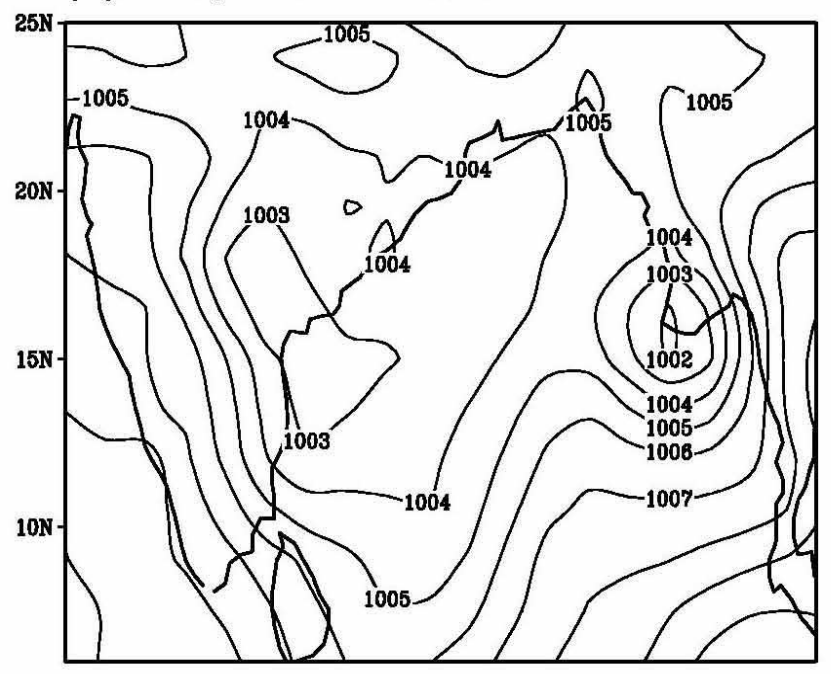

(b) FCST DAY-1 Case-2 by CD.

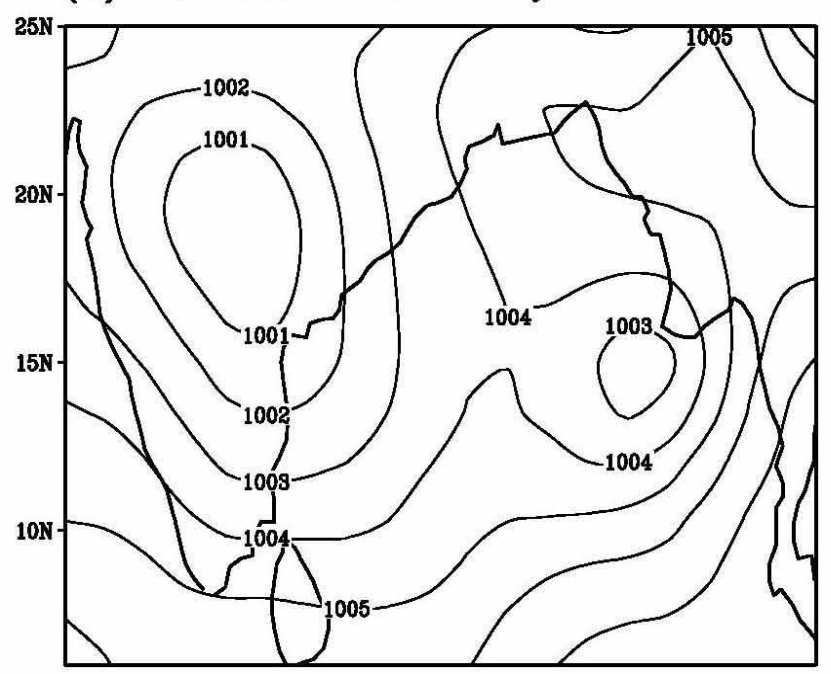

(c) FCST DAY-1 Case-2 by FD.

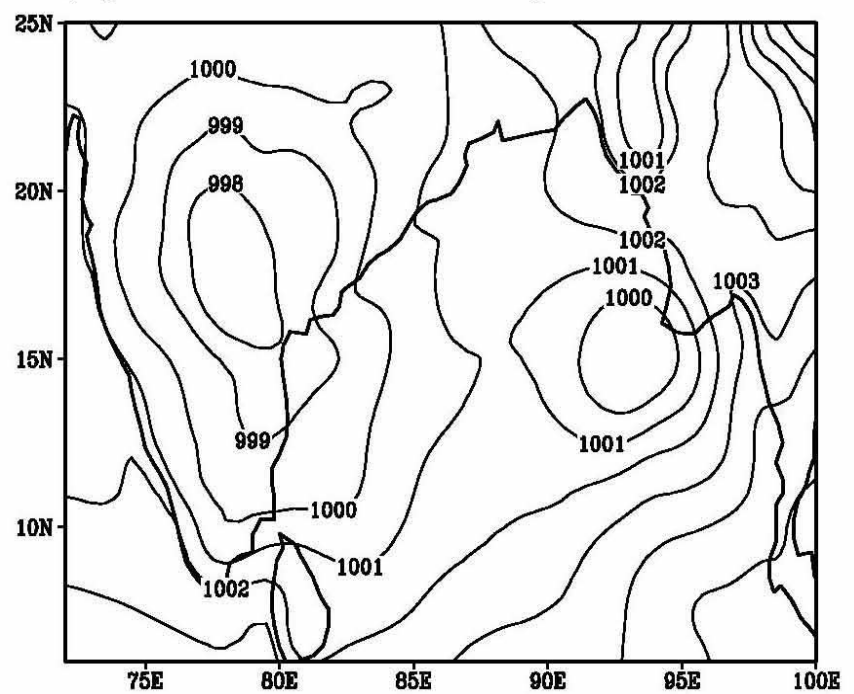

(d) Analysis DAY-2 Case-2.

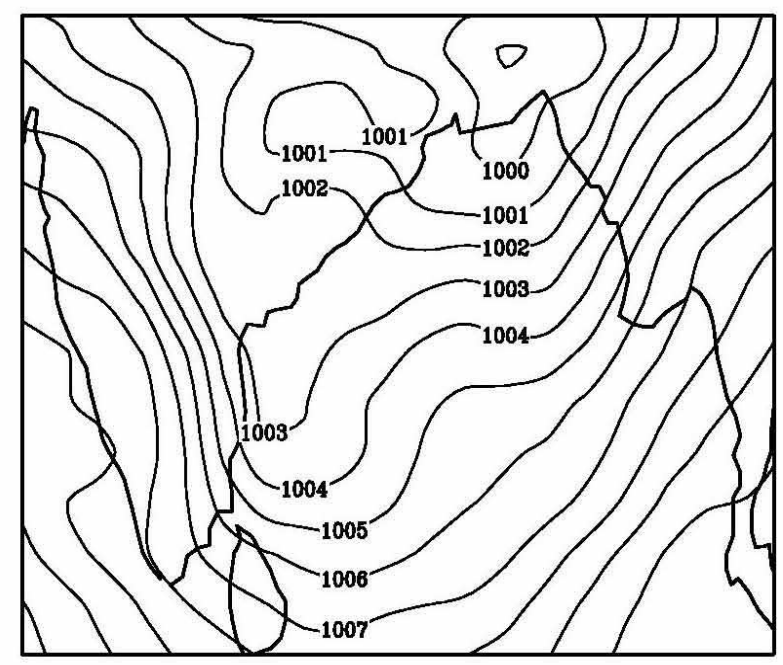

(e) FCST DAY -2 Case -2 by CD.

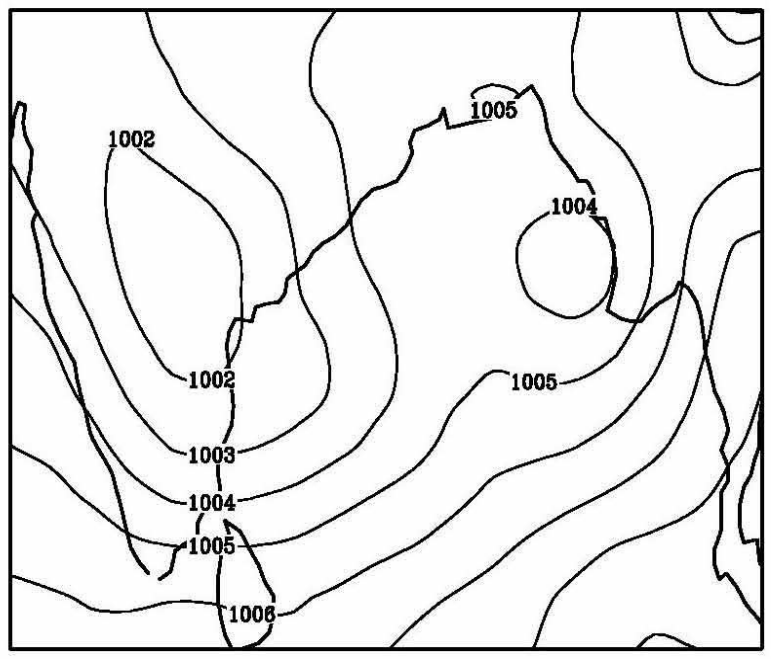

(f) FCST DAY -2 Case-2 by FD.

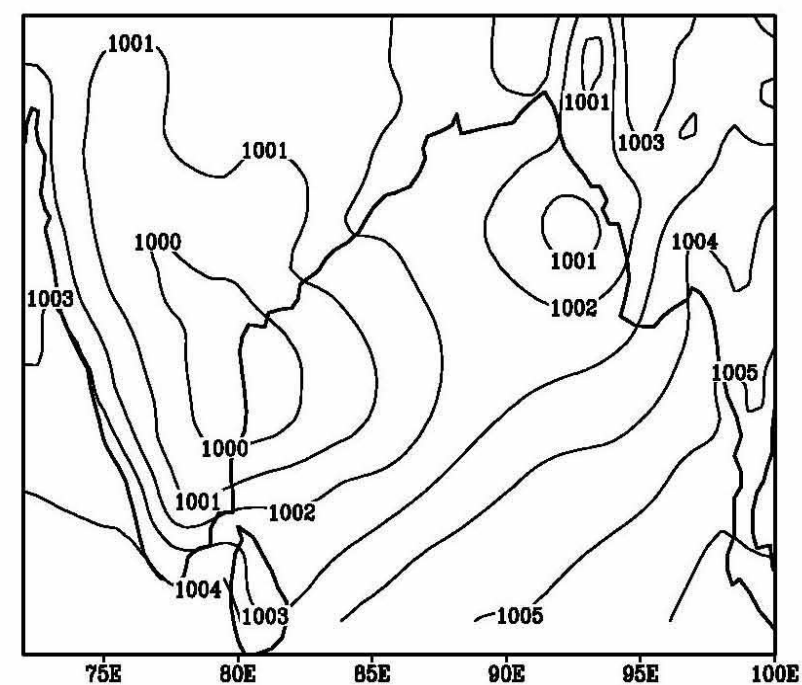

Figure 3. Same as in figure 2 but for case 2 . 
(a) Analysis DAY-1 Case-1.

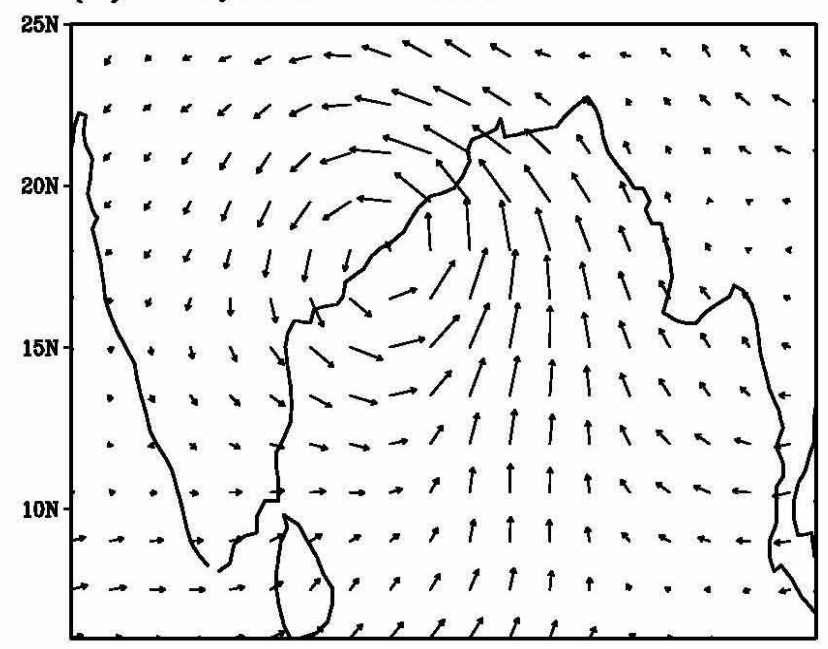

(b) FCST DAY-1 Case-1 by CD. $\overrightarrow{20}$

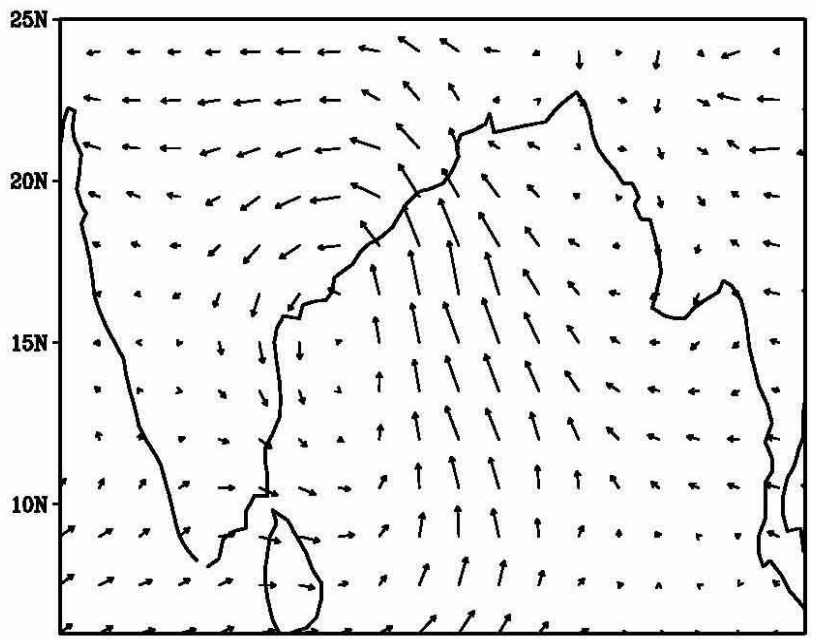

(c) FCST DAY - 1 Case-1 by FD. $\overrightarrow{20}$

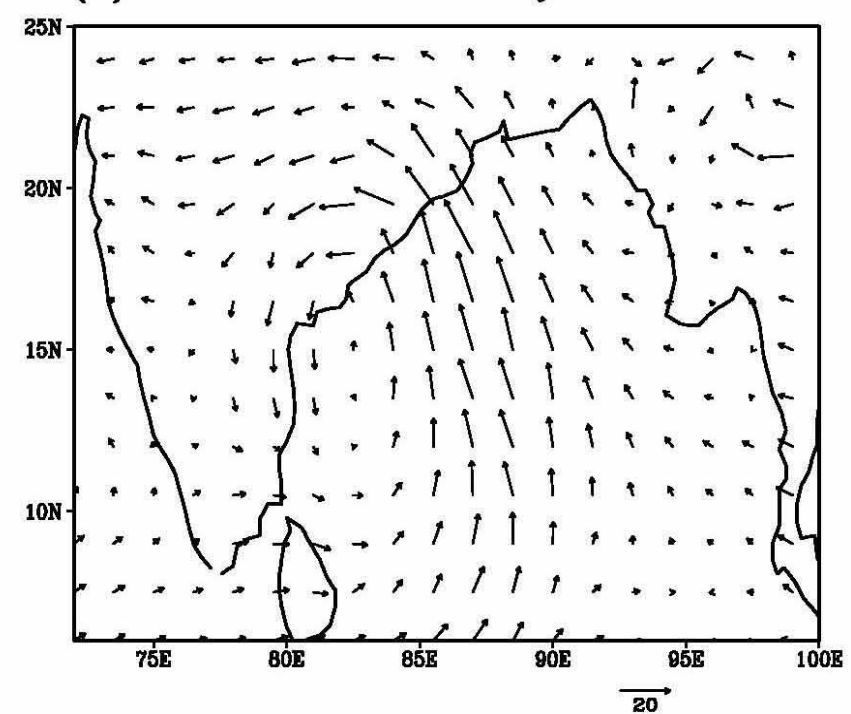

(d) Analysis DAY-2 Case-1.

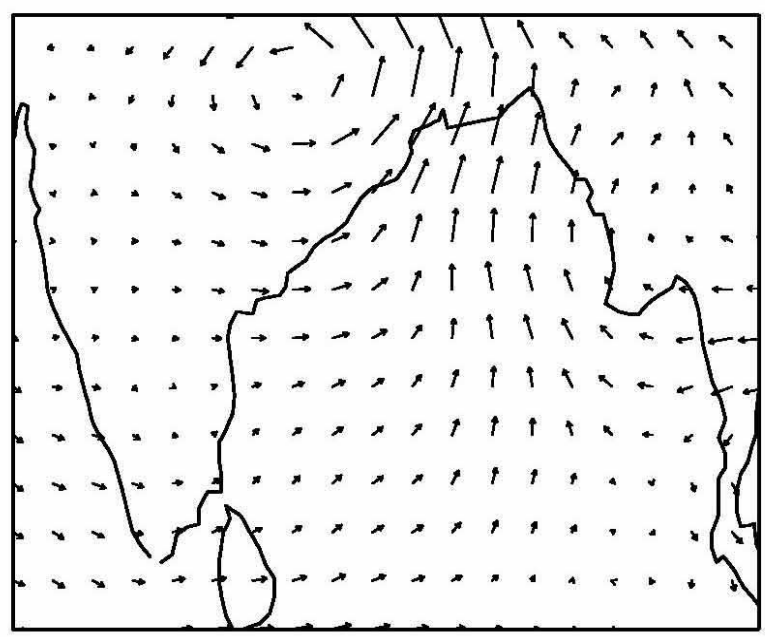

(e) FCST DAY -2 Case-1 by $C \overline{C D}$.

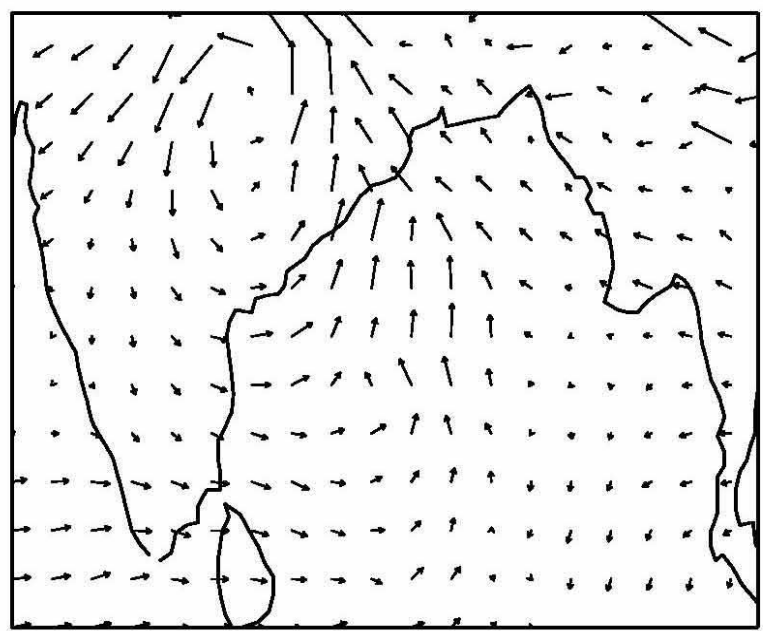

(f) FCST DAY-2 Case-1 by FD. $\overrightarrow{{ }^{20}}$

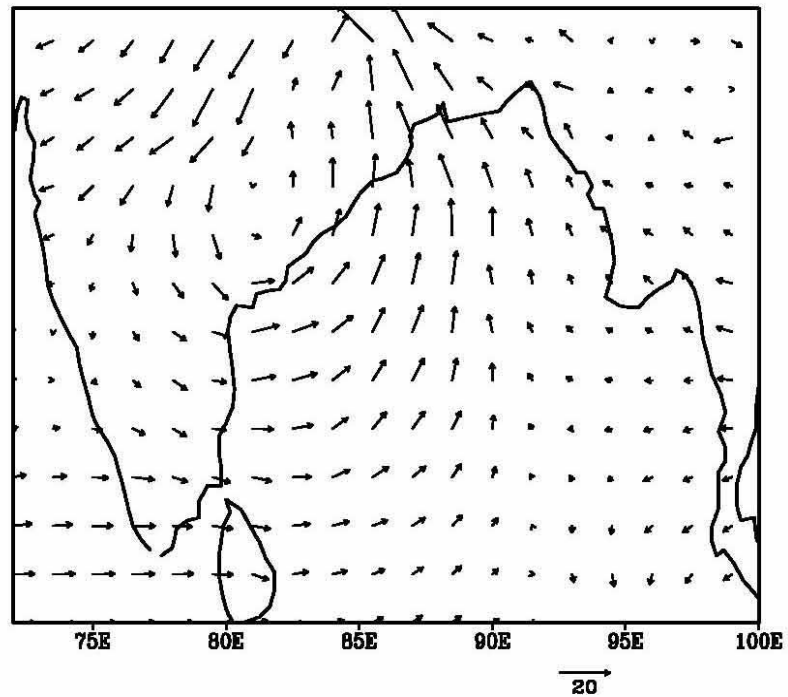

Figure 4. Verification analysis and forecast of wind vector at $850 \mathrm{mb}$ (all at $00 \mathrm{UTC}$ ); (a) analysis on 9th Nov.'95, (b) 24-hours forecast valid on 9th Nov.'95 by coarse domain (CD), (c) 24-hours forecast valid on 9th Nov.'95 by fine domain (FD), (d) analysis on 10th Nov.'95, (e) 48-hours forecast valid on 10th Nov.'95 by coarse domain (CD), (f) 48-hours forecast valid on 10th Nov.'95 by fine domain (FD). 


\section{(a) Analysis DAY -1 Case -1 .}

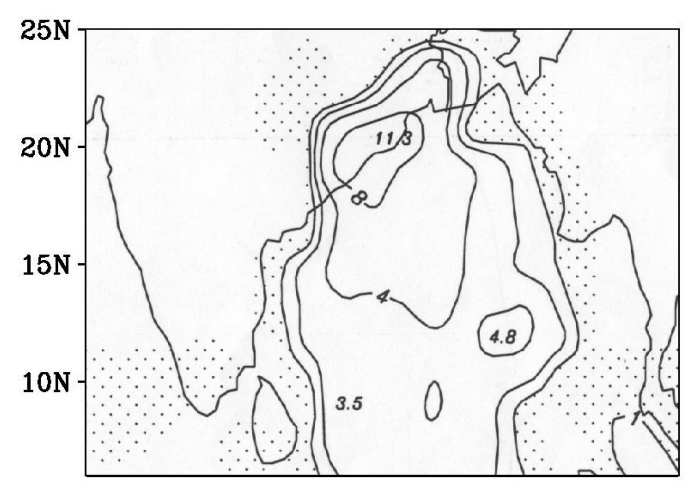

(b) FCST DAY - 1 Case- 1 by CD.

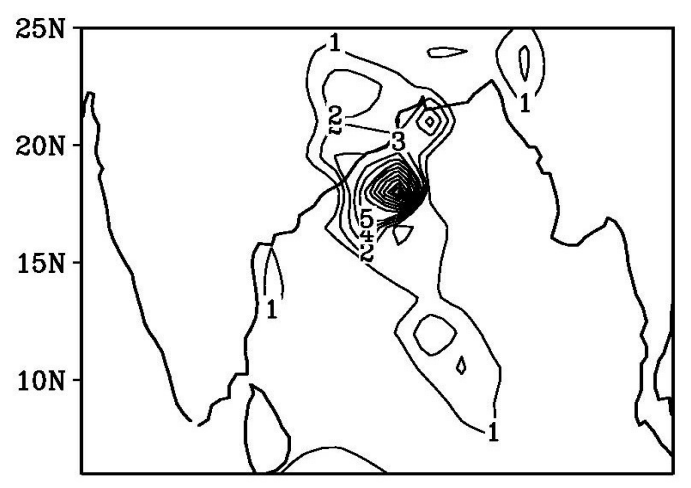

(c) FCST DAY-1 Case-1 by FD.

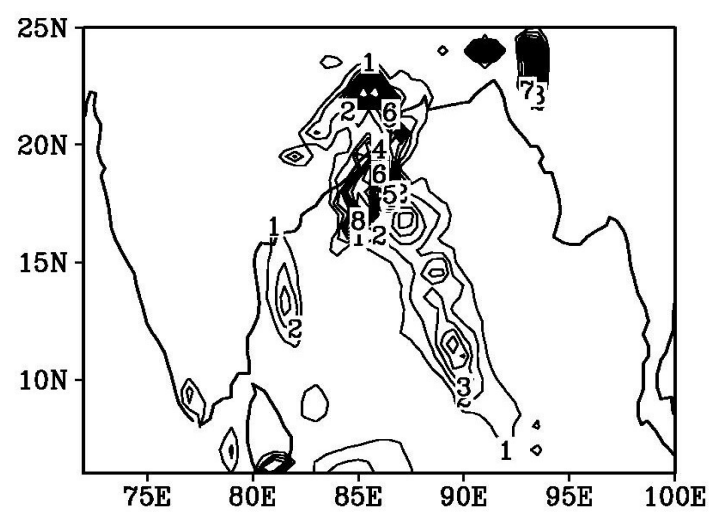

Figure 5. Verification analysis and forecast of 24 hours accumulated rainfall (in $\mathrm{cm}$ ) between 03 UTC 8th Nov.'95 03 UTC 9th Nov.'95; (a) verification analysis, (b) 24-hours forecast by the CD, (c) 24-hours forecast by the FD.

north of Bhubaneshwar. As shown in figure 2(c), there is a trough over coastal Orissa and the maximum precipitation occurred ahead of the trough in FD forecast. Similarly in CD forecast, the maximum precipitation is found to occur ahead of the trough over the Bay of Bengal near the Orissa coast. In both resolutions, the model is not able to predict the location of maximum precipitation (a) Analysis DAY-1 Case-2.

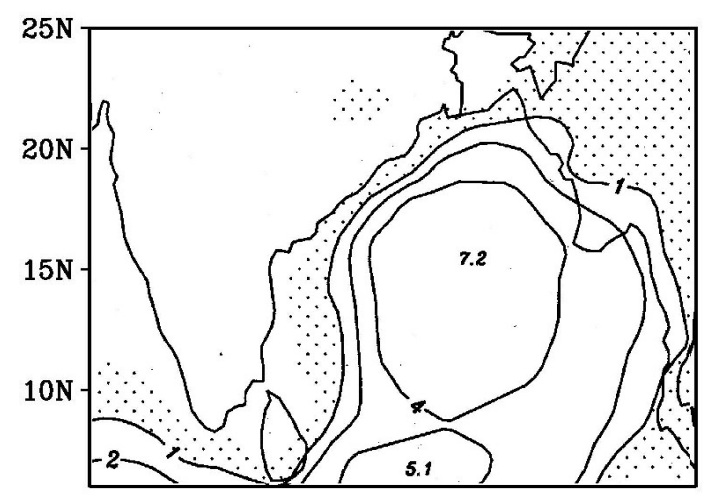

(b) FCST DAY -1 Case- 2 by CD.

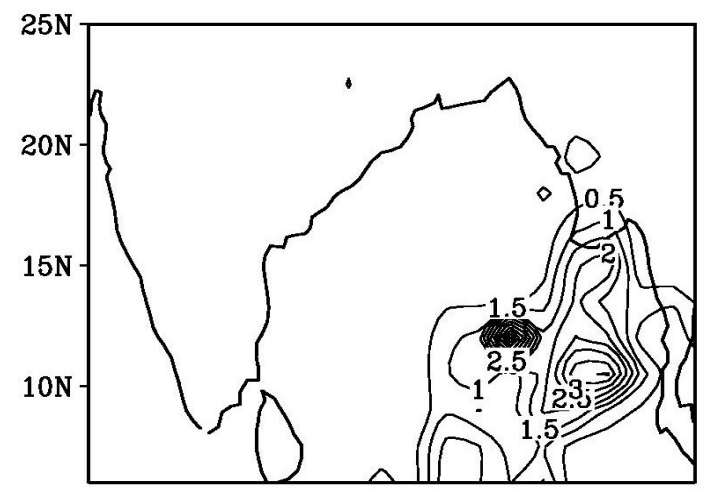

(c) FCST DAY - 1 Case-2 by FD.

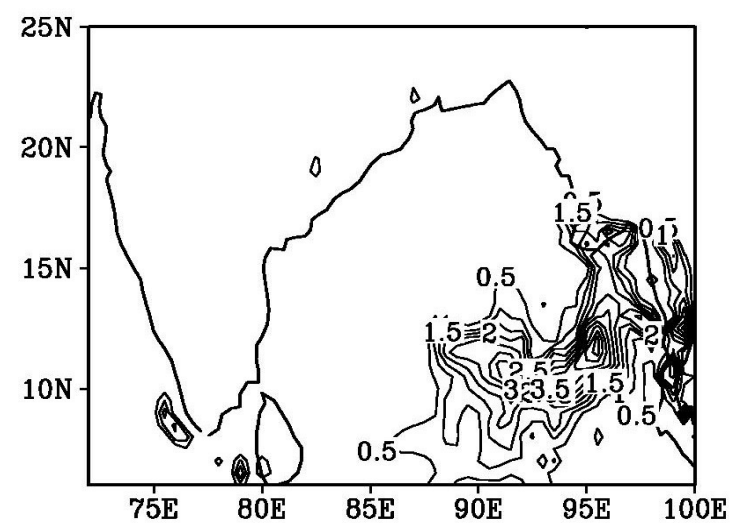

Figure 6. Verification analysis and forecast of 24 hours accumulated rainfall (in $\mathrm{cm}$ ) between 03 UTC 17 May '97 03 UTC 18 May '97; (a) verification analysis, (b) 24-hours forecast by the CD, (c) 24-hours forecast by the FD.

but magnitude of precipitation over coastal Orissa is much better predicted in finer resolution model (FD). It is mainly due to better representation of the topography and better prediction of intensity of the system in finer resolution. The north-south elongation of the system as shown in the mean sea level pressure and wind field is in agreement with the precipitation analysis. 
Figure 6(a) shows analysis of 24 hours accumulated precipitation valid at 0300 UTC of 18th May 1997. This shows maximum precipitation of $7.2 \mathrm{~cm}$ located around $90^{\circ} \mathrm{E}$ and $15^{\circ} \mathrm{N}$ and precipitation of $4 \mathrm{~cm}$ and $2 \mathrm{~cm}$ over Port Blair and Car Nicobar. Figure 6(b) and (c) shows CD and FD forecast of 24 hours accumulated precipitation valid at 0300 UTC of 18th May 1997 respectively. FD forecast shows maximum precipitation of $5 \mathrm{~cm}$ around $96^{\circ} \mathrm{E}$ and $12^{\circ} \mathrm{N}$. $3 \mathrm{~cm}$ and $2 \mathrm{~cm}$ of precipitation is predicted over Port Blair and Car Nicobar respectively. CD predicts maximum precipitation of $5 \mathrm{~cm}$ around $91.5^{\circ} \mathrm{E}$ and $12^{\circ} \mathrm{N}$. Port Blair and Car Nicobar is found to receive $2 \mathrm{~cm}$ and $1.5 \mathrm{~cm}$ rainfall respectively in $\mathrm{CD}$ forecast. Here also the maximum rainfall was found to be along the trough in the south and southeast sector of the system in the CD and FD forecast respectively. As mentioned earlier, the improvement in precipitation forecast with increase in resolution is mainly due to better representation of orography in finer resolution. In this case, the maximum precipitation is found to be over the ocean. Probably that is the reason behind no improvement in maximum precipitation forecast in finer resolution. But precipitation over Port Blair and Car Nicobar is better simulated in FD forecast.

\subsection{Some important diagnostic fields}

Relative vorticity field at $850 \mathrm{hPa}$ as obtained from analysis valid for 0000 UTC of 9th November 1995 is shown in figure 7 (a). High positive vorticity of $150 \times 10^{-6} \mathrm{sec}^{-1}$ is observed over the storm center. Figure $7(\mathrm{~b})$ and (c) illustrates relative vorticity at $850 \mathrm{hPa}$ valid for $0000 \mathrm{UTC}$ of 9 th November 1995 as obtained from day- 1 forecast of CD and FD respectively. Both figures show high positive relative vorticity over the predicted storm center. CD forecast shows positive vorticity of $70 \times 10^{-6} \mathrm{sec}^{-1}$ whereas FD forecast was able to produce positive vorticity of $110 \times 10^{-6} \mathrm{sec}^{-1}$, which is close to the actual. This may be due to the fact that a finer resolution model is able to resolve curvature and shear effects better.

The horizontal divergence at $850 \mathrm{hPa}$ as obtained from analysis, CD and FD forecasts are presented in figure 8(a), (b) and (c) respectively valid at 0000 UTC of 9th November 1995. Both in the analysis and CD forecast convergence of the order of $30 \times 10^{-6} \mathrm{sec}^{-1}$ is observed over the northeast sector of the storm. Increase in resolution produces three cells of strong convergence. One is close to the center of the storm. The other is over south Andhra coast coincident with secondary precipitation maxima and the third in the southern Bay, which is in agreement with precipitation presented in figure $5(\mathrm{c})$. Weak divergence amongst three conver- (a) Analysis DAY-1 Case-1.

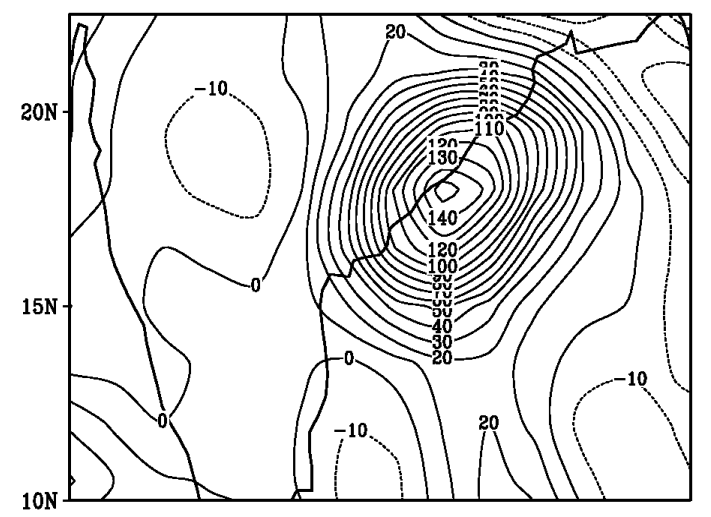

(b) FCST DAY-1 Case-1 by CD.

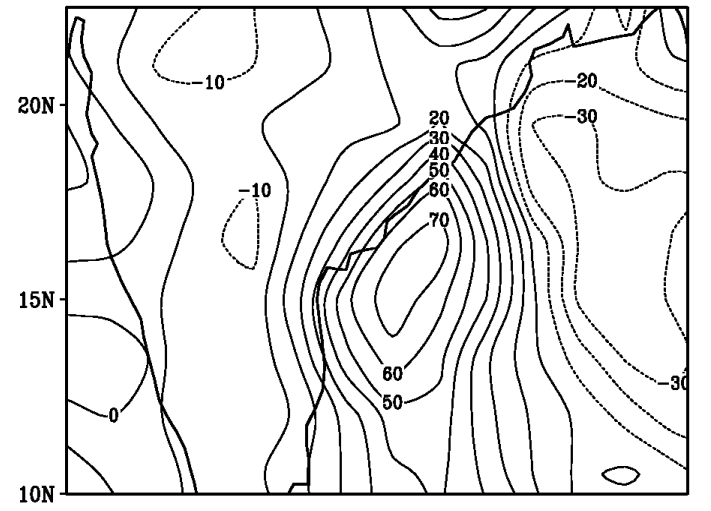

(c) FCST DAY-1 Case-1 by FD.

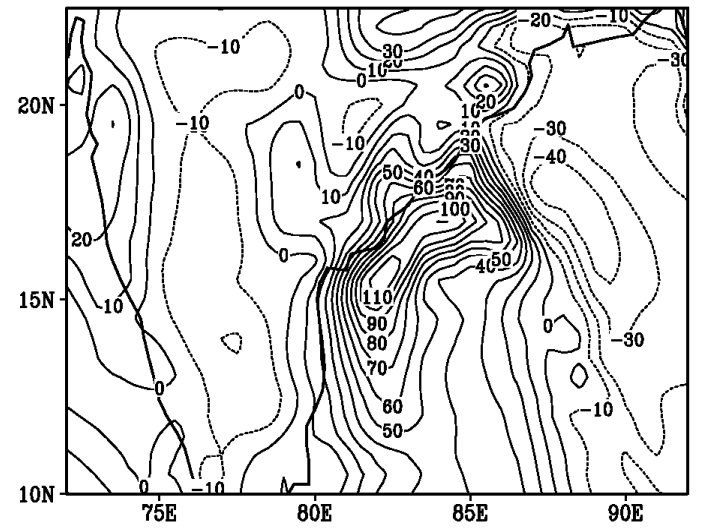

Figure 7. Verification analysis and forecast of relative vorticity $\left(10^{-6} \mathrm{sec}^{-1}\right)$ at $850 \mathrm{mb}$ (all at 00 UTC); (a) Verification analysis valid at 9th Nov.'95, (b) 24-hours forecast valid at 9th Nov.'95 by the CD, (c) 24-hours forecast valid at 9 th Nov.' 95 by the FD.

gence centres could be due to the possible descending motion between two splitted cells of the vortex.

Figure $9(\mathrm{a})$ to (c) represents diabatic heating at $500 \mathrm{hPa}$ as obtained from analysis, 24 hours CD and FD forecasts respectively valid for 0000 UTC of 9th November. Diabatic heating is observed over the region of maximum precipitation in analysis, $\mathrm{CD}$ and FD forecasts. Diabatic cooling is observed 
(a) Analysis DAY-1 Case-1.

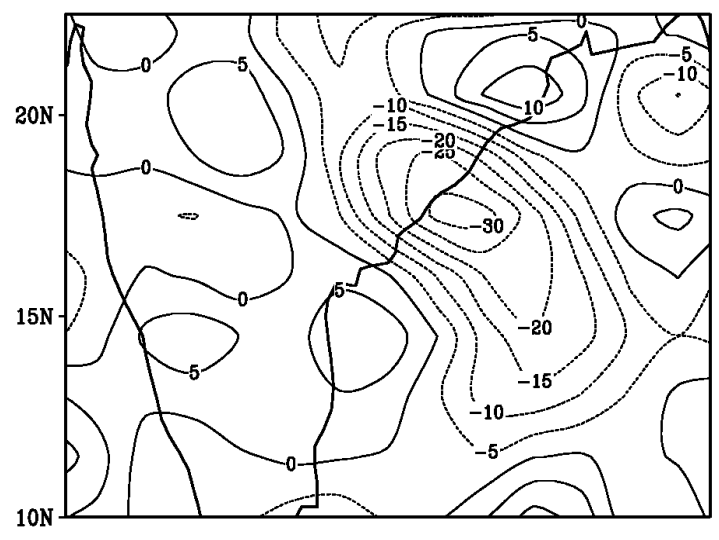

(b) FCST DAY-1 Case-1 by CD.

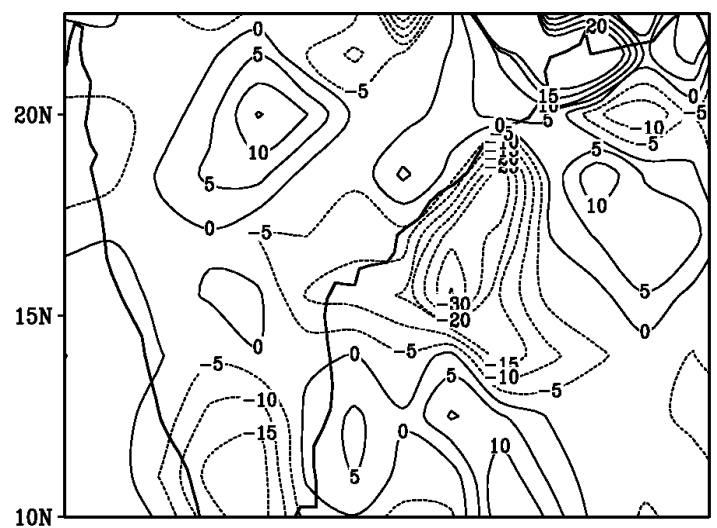

(c) FCST DAY -1 Case-1 by FD.

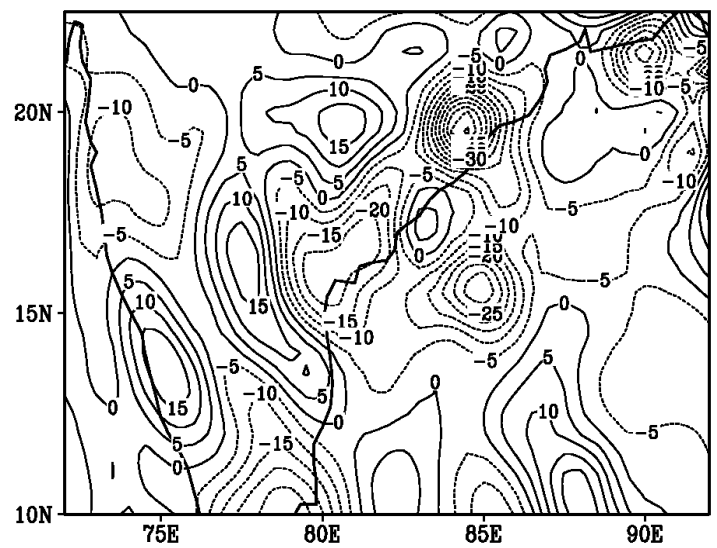

Figure 8. Verification analysis and forecast of horizontal divergence $\left(10^{-6} \mathrm{sec}^{-1}\right)$ at $850 \mathrm{mb}$ (all at $00 \mathrm{UTC}$ ); (a) Verification analysis valid at 9th Nov.'95, (b) 24-hours forecast valid at 9 th Nov.'95 by the CD, (c) 24-hours forecast valid at 9th Nov.' 95 by the FD.

over the storm area at lower levels (figures not present). The cooling could be due to evaporation of falling rain and initial lifting from lower levels with non-compensated latent heat release due to cloud formation. At $700-400 \mathrm{hPa}$, where large thick clouds are formed and precipitation is not intense, the heating outweighs the cooling effect (a) Analysis DAY-1 Case-1.

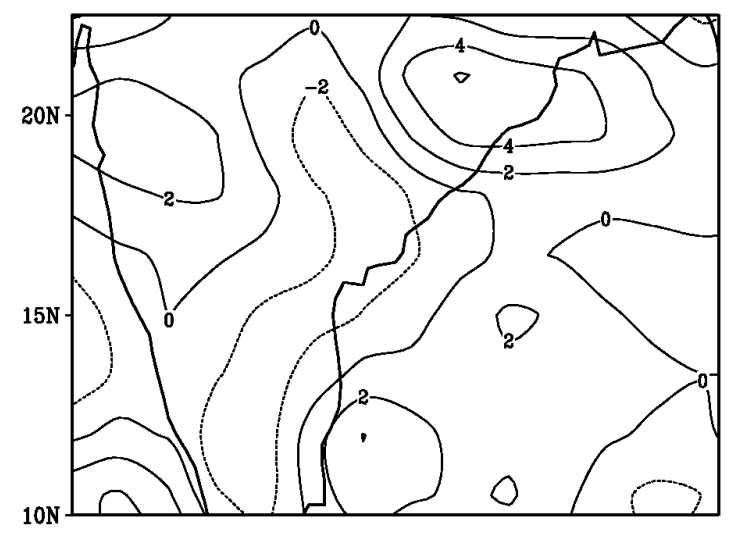

(b) FCST DAY-1 Case-1 by CD.

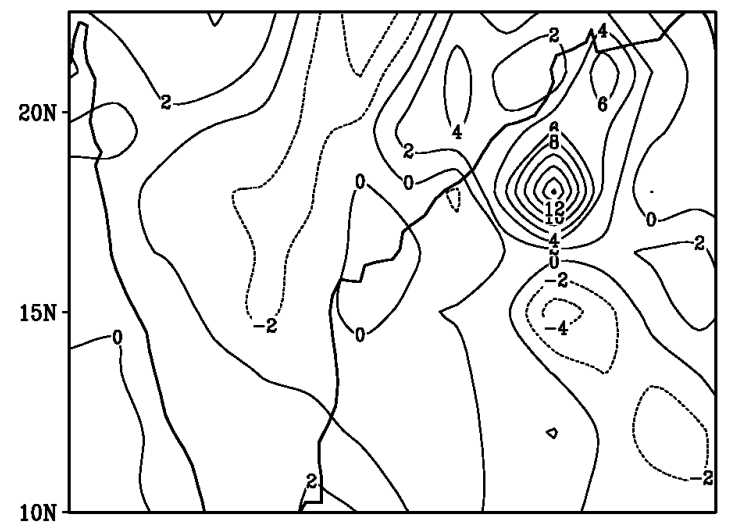

(c) FCST DAY-1 Case-1 by FD.

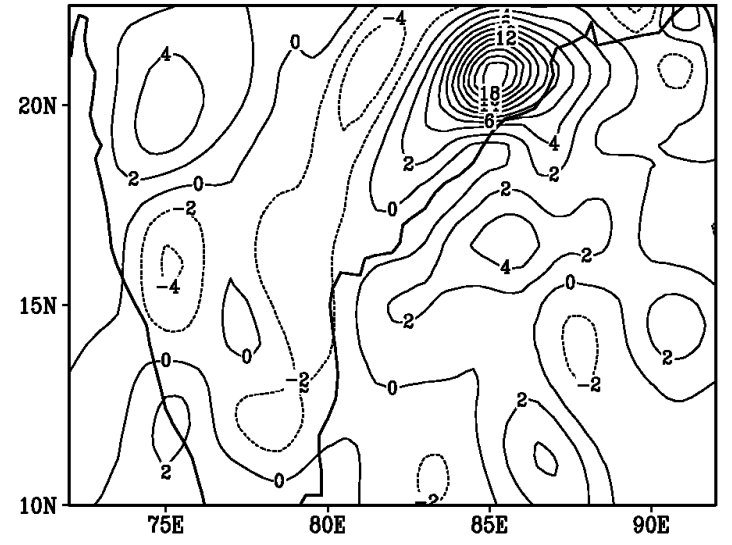

Figure 9. Verification analysis and forecast of diabatic heating (Watt $/ \mathrm{m}^{2}$ ) at $500 \mathrm{mb}$ (all at $00 \mathrm{UTC}$ ); (a) Verification analysis valid at 9th Nov.'95, (b) 24-hours forecast valid at 9th Nov.' 95 by the CD, (c) 24-hours forecast valid at 9th Nov.' 95 by the FD.

due to falling rain and sinking of part of the air. FD forecast gives more strong heating than analysis and CD forecast and also the position of maximum heating matches more accurately with the position of maximum precipitation (figure $5 \mathrm{c}$ ).

The horizontal moisture flux at $850 \mathrm{hPa}$ as obtained from analysis, 24 hours $\mathrm{CD}$ and FD 
(a) Analysis DAY-1 Case- 1 .

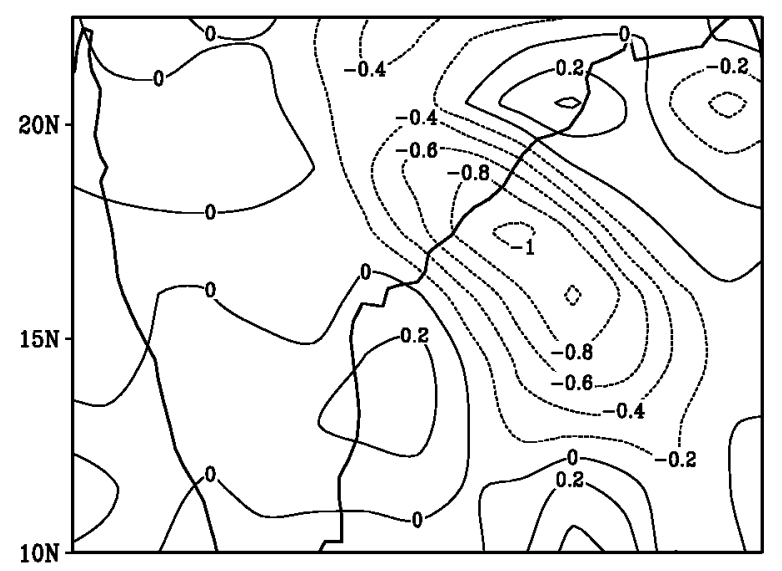

(b) FCST DAY-1 Case-1 by CD.

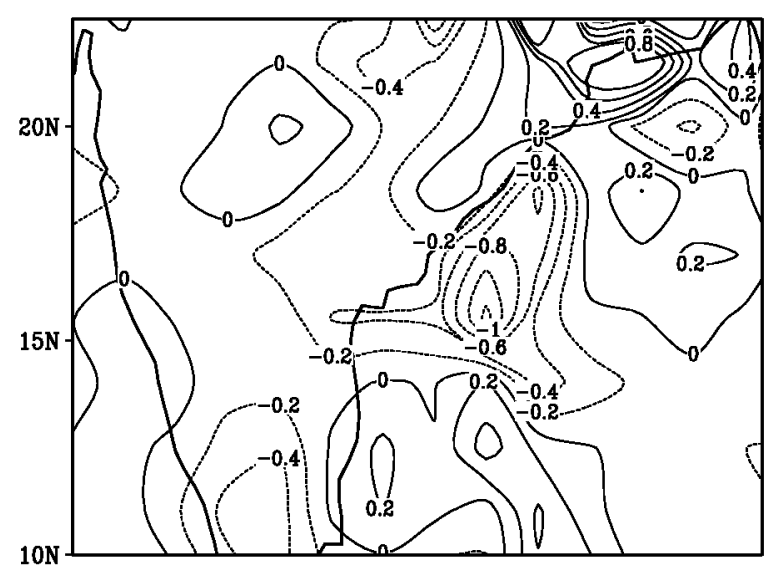

(c) FCST DAY -1 Case- 1 by FD.

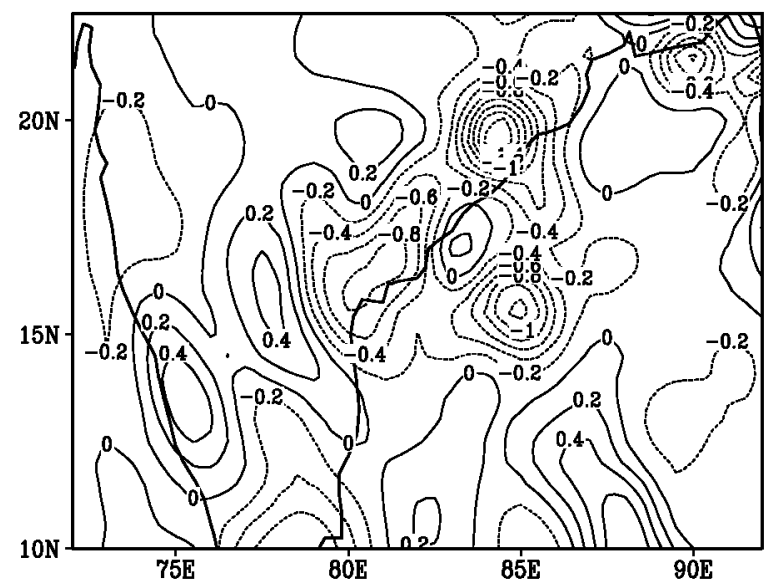

Figure 10. Verification analysis and forecast of horizontal moisture flux (Watt $/ \mathrm{m}^{2}$ ) at $850 \mathrm{mb}$ (all at $00 \mathrm{UTC}$ ); (a) verification analysis valid at 9th Nov.'95, (b) 24-hours forecast valid at 9 th Nov.'95 by the CD, (c) 24-hours forecast valid at 9th Nov.' 95 by the FD.

forecasts valid for 0000 UTC of 9th November 1995 are shown in figure 10(a) to (c) respectively. Strong horizontal convergence of moisture flux of the order of $1 \mathrm{Watt} / \mathrm{m}^{2}$ is observed over the storm in analysis and CD forecast. FD forecast shows still stronger convergence of moisture over an area of about $\pm 4^{\circ}$ latitude/longitude of the storm. Here also a very small region of divergence is observed due to the breakup of the vortex into two cells as discussed earlier. This area of moisture convergence matches reasonably well with the area of heavy precipitation. The divergence of moisture flux is observed in the outer core region beyond $4^{\circ}$ lat./long. These areas act as a source of moisture through evaporation of water vapor.

Although the diagnostic fields obtained from CD forecast are found to match reasonably well with that obtained from analysis, the diagnostic fields obtained from FD forecast are more realistic for a mature cyclone and consistent to each other.

\subsection{Track}

The tracks of the cyclones for both case 1 and case 2 are compared with the track obtained from the NCMRWF analysis and the best-fit track obtained from IMD. Figure 11(a) shows track of the cyclone for case 1 with location of the storm in every 12 hours. In case 1 , the storm is found to be centered near $13^{\circ} \mathrm{N}$ and $88.5^{\circ} \mathrm{E}$ at 0000 UTC of 8 th November 1995. It has moved northward and intensified into severe cyclonic storm with a core of hurricane wind and lay close to north Andhra Pradeshsouth Orissa coast with its center near $18^{\circ} \mathrm{N}$ and $85.1^{\circ} \mathrm{E}$ at $0000 \mathrm{UTC}$ of 9 th November. It crossed north Andhra Pradesh-Orissa coast between Kalingapatnam and Gopalpur around 0500 UTC of 9th November 1995. After landfall, the storm gradually weakened and moved northward and located near $24^{\circ} \mathrm{N}$ and $85^{\circ} \mathrm{E}$ at $0000 \mathrm{UTC}$ of 10 th November. According to the NCMRWF analysis the center of the cyclone was located near $12^{\circ} \mathrm{N}$ and $85.5^{\circ} \mathrm{E}$ at 0000 UTC of 8th November 1995 with an initial position error of $344 \mathrm{~km}$. This is used as initial condition to the model. Although the tracks obtained from CD and FD forecasts are found to be to the west of the observed track as well as that obtained from analysis, the track is clearly better predicted in the FD forecast.

Figure 11(b) illustrates the track of the cyclone for case 2 as obtained from IMD observation, the NCMRWF analysis and CD and FD forecasts. The observation shows the locations of the storm center at 0000 UTC of 17th, 18th and 19th May 1997 near $11^{\circ} \mathrm{N}-91.4^{\circ} \mathrm{E}, 16^{\circ} \mathrm{N}-91^{\circ} \mathrm{E}$ and $20^{\circ} \mathrm{N}-90.8^{\circ} \mathrm{E}$ respectively. The NCMRWF analysis valid for 0000 UTC on 17th shows the center of the storm located at $12^{\circ} \mathrm{N}-91.5^{\circ} \mathrm{E}$ with an initial position error of $112 \mathrm{~km}$. In this case, model predicted tracks obtained from CD and FD forecasts are found to be to the east of the observed track. The track obtained from the analysis is found to 
(a)

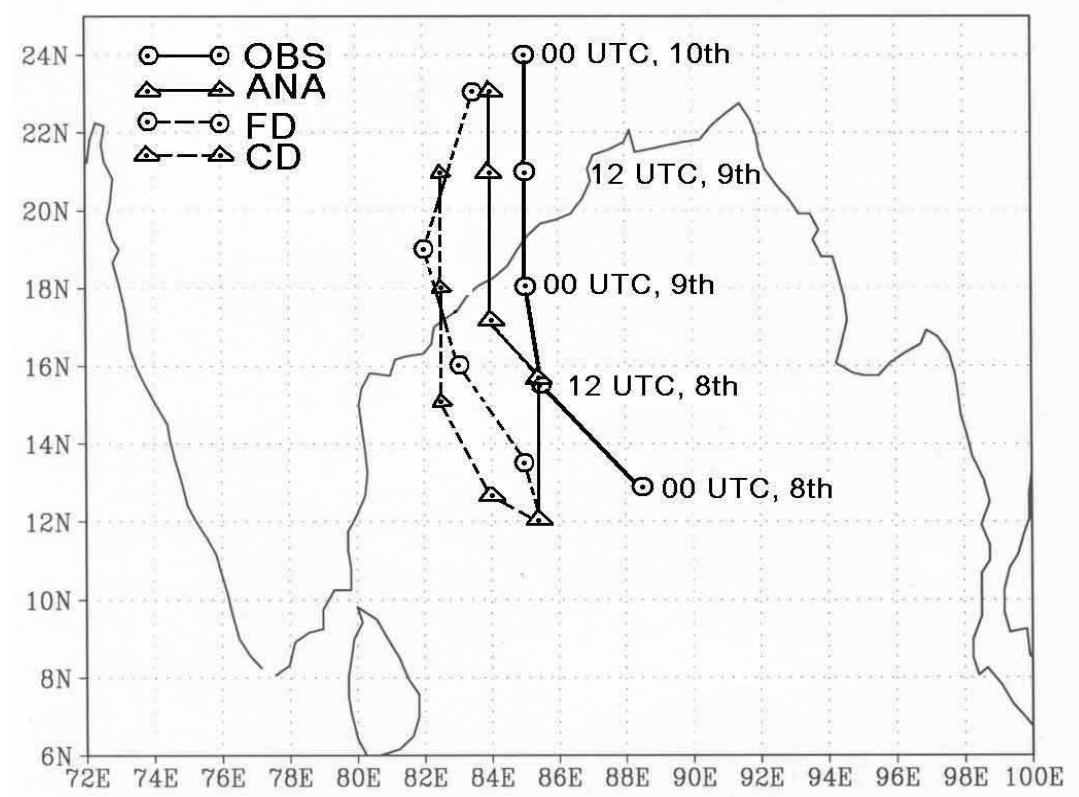

(b)

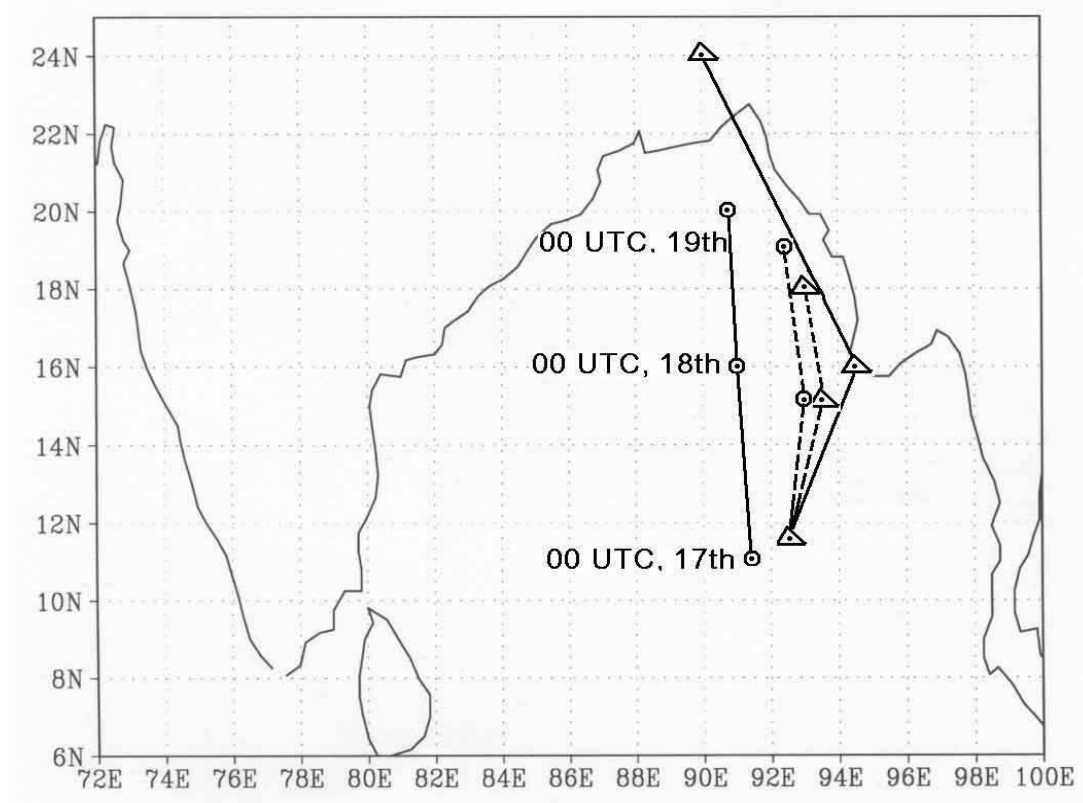

Figure 11. Track of the cyclone as obtained from IMD (best-fit track), NCMRWF analysis and model simulation; (a) during 8th-10th November 1995, (b) during 17th-19th May 1997.

be deviated further from the observed than the predicted tracks. In this case also, the track is found to be slightly better predicted in FD forecast. The vector displacement error in track forecast for both the cases is given in table 2 . It clearly indicates that the track of the cyclone is consistently better predicted in finer domain. Only in the 24 hours forecast of case 2, the error with respect to analysis is found to be less in low resolution, which is due to the error in the verification analysis.

\section{Conclusions}

A regional hydrostatic weather prediction model has been used to examine the impact of horizontal resolution in simulating cyclones formed over the Bay of Bengal. As expected, results improved with increase in horizontal resolution. The intensity of the storm and its track are superior in the simulation results of the finer resolution model as compared to that of the lower resolution. 
Table 2. Error in track forecast (in $\mathrm{km}$ ).

\begin{tabular}{|c|c|c|c|c|}
\hline \multicolumn{5}{|c|}{ Case 1} \\
\hline \multirow{2}{*}{$\begin{array}{c}\text { Forecast time } \\
\text { (in hours) }\end{array}$} & \multicolumn{2}{|c|}{ w.r.t NCMRWF Analysis } & \multicolumn{2}{|c|}{ w.r.t Observation } \\
\hline & Low resolution & High resolution & Low resolution & High resolution \\
\hline 12 & 370.7 & 250.4 & 350.8 & 228.8 \\
\hline 24 & 283.2 & 162.2 & 433.7 & 315.1 \\
\hline 36 & 368.8 & 305.1 & 424.2 & 384.3 \\
\hline 48 & 270.8 & 51.2 & 421.0 & 189.1 \\
\hline
\end{tabular}

Case 2

\begin{tabular}{c|c|c|c|c}
\hline Forecast time & \multicolumn{2}{|c|}{ w.r.t NCMRWF Analysis } & \multicolumn{2}{c}{ w.r.t Observation } \\
\cline { 2 - 5 } (in hours) & Low resolution & High resolution & Low resolution & High resolution \\
\hline 24 & 154.4 & 195.4 & 290.0 & 241.4 \\
48 & 736.3 & 613.2 & 320.9 & 210.0 \\
\hline
\end{tabular}

The magnitude and distribution of precipitation is found to be very sensitive to the model horizontal resolution and hence topography representation. The magnitude and spatial distribution of rainfall is better simulated in the finer domain model.

The diagnostic fields like, horizontal divergence, vertical velocity and horizontal moisture flux also show that the model is sensitive to horizontal resolution.

The model horizontal resolution has a positive impact in the prediction of the track of the storms. The tracks of both the cyclones that are simulated in the present study are better simulated in the finer domain model.

\section{Acknowledgements}

The authors gratefully acknowledge the NCMRWF for providing their analyzed data sets for the present study. The authors also owe thanks to the India Meteorological Department for providing precipitation data and observed track of the storms for the study. The Council of Scientific and Industrial Research (CSIR) is gratefully acknowledged for providing financial support to the first author. The work is partially financed by Naval Research Laboratory, Washington D.C., USA.

\section{References}

Anthes R A 1977 A cumulus parameterization scheme utilizing a one-dimensional cloud model; Mon. Weather Rev. $105270-286$

Bhaskar Rao D V and Ashok K 1999 Simulation of tropical cyclone circulation over Bay of Bengal using the ArakawaSchubert cumulus parameterization. Part I - Description of the model, initial data and results of the control experiment; Pure and Applied Geophysics 156 525-542

Braun S A and Tao W -K 2000 Sensitivity of high-resolution simulations of hurricane Bob (1991) to planetary boundary layer parameterizations; Mon. Weather Rev. 128 3941-3961
Giorgi F and Marinucci M R 1996 An investigation of sensitivity of simulated precipitation to model resolution and its implication for climate studies; Mon. Weather Rev. $124148-166$

Gupta Akhilesh and Bansal R K 1997 Performance of a Global Spectral Model in predicting the track of a hurricane in the Bay of Bengal using synthetic vortex; Dept. of Sci. E Tech., New Delhi (NCMRWF) Tech. Report, August, $199 \%$.

Iwasaki T, Nakano H and Sugi M 1987 The performance of typhoon track prediction model with cumulus parameterization; J. Meteor. Soc. Japan $65555-570$

Karyampudi V M, Lai G S and Manobianco J 1998 Impact of initial condition, rainfall assimilation and cumulus parameterization on simulation of Hurricane Florance (1988); Mon. Weather Rev. 126 3077-3101

Krishnamurti T N 1990 Monsoon prediction a different resolution with a global spectral model; Mausam $41234-$ 240

Kuo H L 1974 Further studies of parameterization of the influence of cumulus convection on large-scale flow; $J$. Atmos. Sci. 31 1232-1240

Kurihara Y, Bender M A, Tuleya R E and Ross R J 1993 Hurricane forecasting with GFDL automated prediction system; Preprints $20^{\text {th }}$ Conf. Hurr. Trop. Meteor., Amer. Meteor. Soc., Boston, MA02 108 323-326

Kurihara Y, Bender M A, Tuleya R E and Ross R J 1995 Improvements in the GFDL hurricane prediction system; Mon. Weather Rev. 123 2791-2801

Liu Y, Zhang D -L and Yau M K 1997 A multi-scale numerical simulation of hurricane Andrew (1992). Part-I: Explicit simulation and verification; Mon. Weather Rev. 125 3073-3093

Liu Y, Zhang D -L and Yau M K 1999 A multi-scale numerical simulation of hurricane Andrew (1992). Part-II: Kinematics and inner core structure; Mon. Weather Rev. 127 $2597-2616$

Madala R V 1978 Efficient time integration schemes for atmosphere and ocean. Finite difference techniques for the vectorized fluid dynamics calculations; Springer Verlag 56-74

Madala R V, Chang S W, Mohanty U C, Madan S C, Paliwal R K, Sarin V B, Holt T and Sethu Raman 1987 Description of Naval Research Laboratory Limited Area Dynamical Weather Prediction Model; N.R.L. Tech. Report 5992, Washington D.C., 131 pp.

Mathur M B 1991 The National Meteorological Center's quasi-Lagrangian model for hurricane prediction; Mon. Weather Rev. 109 1419-1447 
Mohanty U C and Mandal M 2003 Simulation of Orissa super cyclone (1999) using Psu/NCAR mesoscale model; Natural Hazards (in press)

Patra K, Prabir Santhanam M S, Potty K V J, Tewari M and Rao P L S 2000 Simulation of tropical cyclones using regional weather prediction models; Current Science $\mathbf{7 9}$ $1,70-78$

Perkey D J and Krietzberg W 1976 A time dependent lateral boundary scheme for limited area primitive equation models; Mon. Weather Rev. 104 744-755

Prasad K 1990 Synthetic observations for representation of tropical cyclones in NWP data assimilation systems; Proc. International symposium on assimilation of observations in Meteorology and Oceanography, ClermountFerrand, France, July, 9-13.
Prasad K, Singh B V and Hatwar H R 1992 Objective analysis and track prediction of tropical cyclones with synthetic data; Physical Processes in atmospheric models. (ed) D R Sikka and S S Singh (Wiley Eastern Ltd.) 349363

Prasad K, Rama Rao Y V and Sanjib Sen 1997 Tropical cyclone track prediction by a high resolution limited area model using synthetic observation; Mausam 48 3,351-366

Puri K, Davidson N E, Leslie L M and Lagan L W 1992 The BMRC tropical limited area model; Aust. Meteor. Mag. 40 81-104

Yu Zhongbo, Lakhatakia M N and Barron E J 1999 Modeling of the river-basin response to single-storm events simulated by a mesoscale meteorological model at various resolutions; J. Geo. Res. 104 D16 19675-19689 